\title{
Expectant, Medical, or Surgical Treatment of Spontaneous Abortion in First Trimester of Pregnancy? A Pooled Quantitative Literature Evaluation
}

\author{
John P. Geyman, MD, Lynn M. Oliver, MD, and Sean D. Sullivan, PharmD, PhD
}

Background: Spontaneous abortion is a common problem in everyday clinical practice, accounting for 15 to 20 percent of all recognized pregnancies. The traditional treatment of this problem has been surgical, emptying the uterus by dilatation and curettage (D\&C). Recent therapeutic and laboratory advances call surgical therapy into question for many patients. It is believed that this pooled quantitative literature evaluation is the first with the goal to clarify the roles of expectant, medical, and surgical treatment of this common problem.

Methods: The literature review was focused on published studies in the English language of outcomes of therapy for spontaneous abortion in the first trimester. We looked for both observational and randomized controlled trials. A successful outcome of treatment required that three criteria be met: vaginal bleeding stopped by 3 weeks, products of conception fully expelled by 2 weeks, and absence of complications. Pooled weighted average success estimates and standard errors were determined for each study; 95 percent confidence intervals were calculated for each form of treatment. Sensitivity analysis compared randomized controlled trials with observational studies for both expectant and surgical treatment.

Results: of the 31 studies retrieved, 18 met inclusion criteria, including 9 involving expectant treatment ( 545 pooled patients), 3 for medical treatment (prostaglandin or antiprogesterone agents) (198 pooled patients), and 10 for surgical treatment (D\&C) (1408 pooled patients). Successful outcomes were found in 92.5 percent of patients receiving expectant treatment, in 93.6 percent of those undergoing $D \& C$, and in 51.5 percent of patients receiving medical treatment.

Conclusions: Expectant management of spontaneous abortion in the first trimester is safe and effective for many afebrile patients whose blood pressure and heart rate are stable and who have no excess bleeding or unacceptable pain. Transvaginal sonographic studies might be useful in patient selection, and serial chorionic gonadotropin monitoring should be considered while observing the initial course of expectant treatment. Currently there is insufficient evidence to support medical therapy of spontaneous abortion, and further research is needed to clarify the more limited role of surgical treatment. (J Am Board Fam Pract 1999;12:55-64.)

Spontaneous inevitable or incomplete abortion in the first trimester of pregnancy is a common problem in everyday clinical practice, accounting for 15 to 20 percent of all recognized pregnancies. ${ }^{1,2}$ The occurrence of pregnancy loss is even higher, because many early zygotes are lost before pregnancy is apparent. ${ }^{1}$ It has been estimated that 25 percent of women will have at least one spontaneous abortion during their reproductive years. ${ }^{3}$

Submitted, revised, 28 August 1998.

From the Department of Family Medicine (JPG, LMO), University of Washington, and the Department of Pharmacy and Health Services (SDS), University of Washington Medical Center, Seattle. Address reprint requests to John P. Geyman, MD, Department of Family Medicine, Box 354696 , University of Washington, Seattle, WA 98105.
Not all patients with this problem seek medical attention, however, and many are treated outside the hospital, so the actual prevalence of this condition in primary care is unknown. An estimated 130,000 to 230,000 office visits are made each year in the United States for spontaneous abortion. ${ }^{4}$

For the last 50 years the prevailing treatment of spontaneous abortion in industrialized countries has been surgical evacuation of the products of conception by dilatation and curettage (D\&C):5,6 Though commonly performed, D\&C is not an entirely innocuous procedure; aside from the small risk of anesthesia, it has been associated with a 4 to 10 percent rate of early complications, including infection, bleeding, and less frequently injuries to the cervix or uterine perforation. ${ }^{1,7}$ In addition, 
D\&C can be associated with long-term complications including decreased fertility. ${ }^{8-10}$

The basic concept that has supported the widespread use of D\&C in treating spontaneous inevitable or incomplete abortion has been the notion that the sooner the products of conception are evacuated from the uterus, the less chance of excess bleeding or infection. It is often difficult to determine clinically whether a spontaneous abortion is complete. Several developments, however, have begun to call into question the wide use of $D \& C$ under these circumstances. First, the increasing utility and availability of sonography (especially transvaginal) now make it possible to determine quite accurately the status and extent of retained products of conception in the uterus. Second, some recent studies have reported the effectiveness of expectant treatment, whereas others have explored the role of medical treatment through various prostaglandin or antiprogesterone agents in evacuating the uterus without $D \& C$. Third, the ready availability of antibiotics has reduced the risk of infection. And fourth, it is now recognized that D\&Cs for incomplete abortion often fail to recover products of conception. ${ }^{11}$

In view of the high rate of spontaneous abortion in the first trimester, the variable results of studies, and the controversy concerning treatment, we performed a pooled quantitative literature evaluation to investigate the following question: What are the comparative outcomes of expectant, medical, and surgical approaches to treatment of spontaneous inevitable and incomplete abortion during the first trimester of pregnancy? We believe that this evaluation is the first of its type to address this question.

\section{Methods}

\section{Literature Review}

The literature review began with a computerized search of the MEDLINE database of studies published between 1 January 1966 and 15 February 1998, using the key words "incomplete abortion," "therapy," "management," and "curettage"; subject headings were also used for "therapy," "drug therapy," "surgery," "prevention," and "control." In addition, the search was limited to spontaneous, not induced, abortion and to the first trimester. Because interpreters were not available in other languages, the search was focused on the English language literature. The search was ex- tended further to references cited in retrieved articles. In addition, Best Evidence and the Cochrane database were checked for citations, and two experts were contacted by one of the authors (JPG) to select any other published or unpublished work on this subject.

Inclusion criteria included all studies of the outcomes of treatment of spontaneous inevitable or incomplete abortion during the first 13 weeks of pregnancy. Specifically we looked for (1) more than 15 patients treated by expectant, medical, or surgical treatment (this number was chosen in an effort to include most of the studies selected by the literature review); (2) medical treatment with prostaglandin or antiprogesterone agents; (3) surgical treatment including sharp and suction curettage and manual vacuum aspiration; (4) objective outcome data, including evaluation of success in evacuating products of conception from the uterus and rates of complications; and (5) sufficient follow-up of at least 2 weeks to assess outcomes accurately

Exclusion criteria included (1) any other type of abortion, such as induced termination of pregnancy and missed abortion; (2) spontaneous abortion beyond first trimester (about 13 weeks); and (3) patients who had a fever (temperature higher than $100.4^{\circ} \mathrm{F}$ ), unstable blood pressure and heart rate, uncontrolled vaginal bleeding, evidence of endometritis or pelvic inflammatory disease, or findings suggestive of ectopic pregnancy

Although the original intent was to carry out a meta-analysis to address the study question, the literature review yielded only three randomized controlled trials (RCTs) addressing our question (two comparing expectant treatment with surgery that had 190 pooled patients, and one comparing medical with surgical treatment that had 50 patients). Accordingly, whereas the principles of meta-analysis were adhered to as much as possible in the organization and summarization of the data, ${ }^{12}$ we recognized from the outset that formal statistical techniques of meta-analysis would not be possible in analysis of the data. The goal was to go beyond a traditional literature review with application of appropriate quantitative measures in an effort to best evaluate the study question.

\section{Outcome Measures}

On the basis of the literature search, there was some inconsistency of objective outcome mea- 
Table 1. Composite Outcome Measures of Treatment of Spontaneous Abortion.

\begin{tabular}{lcc}
\hline Clinical Criteria & Success & Failure \\
\hline $\begin{array}{l}\text { Vaginal bleeding } \\
\begin{array}{l}\text { Products of conception } \\
\text { (POC) }\end{array}\end{array}$ & $\begin{array}{c}\text { Fully expelled } \\
\text { by 2 weeks }\end{array}$ & $\begin{array}{c}\text { Residual POC } \\
>2 \text { weeks }\end{array}$ \\
$\begin{array}{l}\text { Complications } \\
\text { Infection }\end{array}$ & + \\
Transfusion & - & + \\
Uterine perforation & - & + \\
Hospitalization & - & + \\
Death & - & + \\
\hline
\end{tabular}

sures used by different investigators. To classify the intervention as a success or failure, we had to determine a clinically relevant composite outcome for each study (Table 1). To be counted as a successful outcome, all of the outcome criteria had to be met for each patient. Patient status and outcomes were assessed clinically on follow-up visits without the use of sonography. In two studies the chorionic gonadotropin levels were also used to monitor outcomes of treatment; in those instances, a successful outcome was defined as one in which chorionic gonadotropin levels continuously declined and became negative by 30 days. In most cases, investigators were successful in gaining patient compliance for outpatient follow-up visits. In instances where follow-up was lost or incomplete, these patients or studies were excluded from analysis.

\section{Analysis}

Rules were developed for abstraction of data from retrieved reports meeting inclusion criteria. Two authors (JPG and LMO) abstracted data independently for each study, and all discrepancies were reconciled. One investigator (LMO) was blinded to author(s), journal, title, and year of publication. Each study was reviewed for sample size, treatment method, evaluation criteria, outcomes, adequacy of follow-up, complication rate, and overall success or failure of each type of treatment. No distinction was made between suction and sharp curettage in the case of surgical treatment, unless the two tech-

Table 2. Summary of Studies Meeting Inclusion Criteria for Expectant Treatment of Spontaneous Abortion ( $\mathrm{n}$ - 9).

\begin{tabular}{|c|c|c|c|c|}
\hline Author, Year & $\begin{array}{l}\text { Number of } \\
\text { Patients }\end{array}$ & $\begin{array}{l}\text { Percent } \\
\text { Success }\end{array}$ & $\begin{array}{l}\text { Percent } \\
\text { Failure }\end{array}$ & Comments \\
\hline Chipchase \& James, ${ }^{13} 1997^{\star}$ & 19 & 94.7 & 5.3 & $\begin{array}{l}\text { Randomized expectant vs surgical treatment on basis of } \\
\text { TVS with retained POC }<50 \mathrm{~mm} \text { (AP diameter) } \\
\text { (see also Table } 3 \text { ) }\end{array}$ \\
\hline Kaplan et al, ${ }^{14} 1996$ & 172 & 96.5 & 3.5 & $\begin{array}{l}\text { Expectant treatment group had initial empty uterus by } \\
\text { TVS; average gestational age } 5.8 \text { weeks (included } \\
<8 \text { weeks } L M \text { M }) \text {; long-term follow-up showed } 73 \% \text { of } \\
161 \text { patients who desired to become pregnant did so by } \\
18 \text { months }\end{array}$ \\
\hline Nielsen \& Hahlin, ${ }^{15} 1995^{*}$ & 103 & 76.7 & 23.3 & $\begin{array}{l}\text { Randomized expectant vs surgical treatment based on } \\
\text { TVS showing residual POC or blood clots } 15-50 \mathrm{~mm} \\
\text { (AP diameter) (see also Table } 3 \text { ) }\end{array}$ \\
\hline Chung et al, ${ }^{16} 1994$ & 60 & 88.3 & 11.7 & $\begin{array}{l}\text { Expectant treatment group had initial TVS showing } \\
\text { empty uterus }\end{array}$ \\
\hline Haines et al, ${ }^{17} 1994$ & 32 & 100.0 & 0.0 & $\begin{array}{l}\text { Expectant treatment group had empty uterus by inirial } \\
\text { TV's }\end{array}$ \\
\hline Rulin et al, ${ }^{18} 1993$ & 49 & 98.0 & 2.0 & $\begin{array}{l}\text { Expectant treatment group had empty uterus by initial } \\
\text { TVS }\end{array}$ \\
\hline Mansur, ${ }^{\prime \prime} 1992$ & 43 & 97.7 & 2.3 & $\begin{array}{l}\text { Expectant treatment group had empty uterus by initial } \\
\text { TVS; length of gestation not entirely clear in some cases }\end{array}$ \\
\hline Ben-Baruch et al, ${ }^{19} 1991$ & 46 & 100.0 & 0.0 & $\begin{array}{l}\text { Expectant vs surgical treatment not randomized; type of } \\
\text { treatment selected by attending physician; all patients } \\
\text { were }<10 \text { weeks' gestation with hCG }<500 \mathrm{mIU} / \mathrm{mL} \\
\text { and empty uterus by TVS (see also 'Table } 3 \text { ) }\end{array}$ \\
\hline Letterie et al, ${ }^{20} 1991$ & 21 & 95.2 & 4.8 & $\begin{array}{l}\text { TVS initially negative for POC; } 85 \% \text { of patients } \\
\text { cleared to normal hCG by } 30 \text { days ( } 3 \text { patients took } 35 \text {, } \\
49 \text {, and } 97 \text { days) }\end{array}$ \\
\hline Total & 545 & & & \\
\hline
\end{tabular}

"Randomized controlled trial.

TVS - transvaginal sonography, POC - products of conception, AP - anteroposterior, LMP - last menstrual period, hCG - chorionic gonadotropin. 
Table 3. Summary of Studies Meeting Inclusion Criteria for Medical Treatment of Spontaneous Abortion (n - 3).

\begin{tabular}{|c|c|c|c|c|}
\hline Author, Year & $\begin{array}{c}\text { Number of } \\
\text { Patients }\end{array}$ & $\begin{array}{l}\text { Percent } \\
\text { Success }\end{array}$ & $\begin{array}{l}\text { Percent } \\
\text { Failure }\end{array}$ & Comments \\
\hline de Jonge et al, ${ }^{21} 1995^{*}$ & 23 & 13.0 & 87.0 & $\begin{array}{l}\text { Patients randomized to medical (misoprostol } 400 \mu \mathrm{g} \text { ) or } \\
\text { surgical treatment after pelvic examination showing } \\
\text { dilated cervical os and palpable POC; D\&C } 12-17 \\
\text { hours later if abortion not completed (TVS done if } \\
\text { uncertain); study stopped after } 50 \text { patients }\end{array}$ \\
\hline Chung et al, ${ }^{16} 1994$ & 132 & 44.0 & 56.0 & $\begin{array}{l}\text { Medical treatment patients had empty uterus on initial } \\
\text { TVS, and were given gemeprost vaginal pessaries } \\
\text { (up to } 5 \mathrm{mg} \text { total) }\end{array}$ \\
\hline Henshaw et al, ${ }^{22} 1995$ & 43 & 95.3 & 4.7 & $\begin{array}{l}\text { Medical treatment patients had incomplete abortion on } \\
\text { pelvic examination and TVS; given single dose of } 0.5 \\
\text { mg sulprostone intramuscularly or misoprostol } 400 \mu \mathrm{g} \\
\text { orally; D\&C } 12 \text { - } 18 \text { hours later if no decrease of pain, } \\
\text { bleeding, or uterine size }\end{array}$ \\
\hline Total & 198 & & & \\
\hline
\end{tabular}

"Randomized controlled trial (stopped after 50 patients).

POC - products of conception, D\&C - dilatation and curettage, TVS - transvaginal sonography.

niques were directly compared (comparison was done in one study; in this instance an overall outcome for $\mathrm{D} \& \mathrm{C}$ was also calculated). If other outcomes were reported (eg, subsequent fertility), they were included as comments for the particular study. In some instances, outcomes were estimated when minor problems with clarity or completeness of reported results were not sufficient to exclude the entire study.

In view of the scarcity of RCTs and the small number of pooled RCT patients, inferential statistics, such as pooled odds ratios, could not be calculated. Pooled weighted success averages were calculated for each treatment category. Success averages were derived for each study weighted against numbers of patients in each study; standard errors were also calculated. Confidence intervals (95 percent) were determined for each category of treatment when patients were pooled among individual studies. One sensitivity analysis was done comparing outcomes of RCTs and observational studies for the expectant and surgical treatment groups. Further sensitivity analyses involving differences in outcome variables were not permitted by available follow-up data.

\section{Results}

The literature search retrieved 31 reports of studies dealing with treatment of spontaneous inevitable or incomplete abortion in the first trimester of pregnancy. Of these studies, 18 met inclusion criteria, including 9 involving expectant treatment, 3 involving medical treatment, and 10 involving surgical treatment ( 4 of these had comparisons with expectant or medical treatment). Three of the studies were RCTs, of which two compared expectant with surgical treatment and one compared medical with surgical treatment. One additional RCT compared the surgical techniques of sharp curettage with suction curettage. No other studies were added by the two experts.

Table 2 displays the major features of the nine studies assessing the outcomes of expectant treatment, ${ }^{11,13-20}$ and Table 3 provides similar information for studies of medical treatment. ${ }^{16,21,22}$ Table 4 summarizes the main features of six of the surgical studies, ${ }^{13,15,19,21,23-28}$ together with the other surgical studies being compared with expectant or medical treatment in Tables 2 and 3, respectively.

Thirteen studies ${ }^{29-41}$ were excluded based on established exclusion criteria, most commonly unclear patient population (especially concerning length of gestation or presence or absence of infection), as well as incomplete information on outcome evaluation and follow-up.*

Outcomes for expectant, medical, and surgical treatment of spontaneous incomplete abortion during the first trimester are presented in Table 5. Expectant treatment had an overall success rate of 92.5 percent based on 9 studies representing 545 pooled patients. Only three studies, with 198 pooled patients, were available for analysis of med-

*A list of excluded studies is available by request to the corresponding author. 
Table 4. Summary of Studies Meeting Inclusion Criteria for Surgical Treatment of Spontaneous Abortion (n - 10).

\begin{tabular}{|c|c|c|c|c|c|}
\hline Author & Year & $\begin{array}{l}\text { Number of } \\
\text { Patients }\end{array}$ & $\begin{array}{l}\text { Percent } \\
\text { Success }\end{array}$ & $\begin{array}{l}\text { Percent } \\
\text { Failure }\end{array}$ & Comments \\
\hline Chipchase \& James ${ }^{13 *}$ & 1997 & 16 & 93.8 & 6.2 & $\begin{array}{l}\text { Randomized expectant vs surgical treatment } \\
\text { (Table 2) }\end{array}$ \\
\hline de Jonge et $a^{21 \dagger}$ & 1995 & 27 & 96.0 & 4.0 & $\begin{array}{l}\text { Patients randomized to medical vs surgical } \\
\text { treatment (Table } 3 \text { ) }\end{array}$ \\
\hline Nielsen \& Hahlin ${ }^{15 *}$ & 1995 & 52 & 89.0 & 11.0 & $\begin{array}{l}\text { Randomized expectant vs surgical treatment } \\
\text { (Table 2) }\end{array}$ \\
\hline Verkuyl \& Crowther ${ }^{23 \dagger}$ & 1993 & 270 & 95.6 & 4.4 & $\begin{array}{l}\text { MVA } 97.1 \% \text { success vs } 93.9 \% \text { success for } \\
\text { sharp curettage }\end{array}$ \\
\hline Ben-Baruch et al ${ }^{19}$ & 1991 & 68 & 100.0 & 0.0 & $\begin{array}{l}\text { Expectant vs surgical treatment not } \\
\text { randomized; type of treatment selected by } \\
\text { attending physician; all patients were } \\
<10 \text { weeks' gestation with hCG }<500 \\
\text { mIU/mL and empty uterus by TVS }\end{array}$ \\
\hline Kizza \& Rogo 24 & 1990 & 585 & $\begin{array}{l}92.0 \\
\text { (est) }\end{array}$ & $\begin{array}{l}8.0 \\
\text { (est) }\end{array}$ & $\begin{array}{l}\text { Compared MVA (suction) with sharp D\&C; } \\
\text { successful evacuation of POC in } 97.7 \% \text { of } \\
300 \text { patients with suction D\&C and in } 96.5 \% \\
\text { of } 285 \text { patients with sharp D\&C; sepsis in } \\
5.4 \% \text { and } 6.0 \% \text { of each group, respectively }\end{array}$ \\
\hline Farrell et $\mathrm{al}^{25}$ & 1982 & 111 & $\begin{array}{l}94.0 \\
(\text { est) }\end{array}$ & $\begin{array}{c}6.0 \\
\text { (est) }\end{array}$ & $\begin{array}{l}\text { Evaluated suction D\&C in emergency } \\
\text { department with outpatient follow-up; about } \\
93 \% \text { of patients were in first trimester }\end{array}$ \\
\hline Marshall $^{26}$ & 1971 & 86 & $\begin{array}{l}88.0 \\
\text { (est) }\end{array}$ & $\begin{array}{l}12.0 \\
\text { (est) }\end{array}$ & $\begin{array}{l}\text { Early study of outpatient suction D\&C; } \\
\text { retained POC on repeat sharp D\&C in } 8 \% \text { of } \\
\text { patients and endometritis in } 2 \% \text { of patients. }\end{array}$ \\
\hline Suter et $\mathrm{al}^{27}$ & 1970 & 104 & 94.2 & 5.8 & \\
\hline Tan et $\mathrm{al}^{28}$ & 1969 & 89 & 98.9 & 1.1 & $\begin{array}{l}\text { Initial series of } 124 \text { patients excluded because } \\
\text { study included missed abortion and gestations } \\
\text { more than } 13 \text { weeks; later series of } 89 \text { patients } \\
\text { appeared to meet inclusion criteria }\end{array}$ \\
\hline Total & & 1,408 & & & \\
\hline
\end{tabular}

\footnotetext{
*Randomized controlled trial.
}

tRandomized controlled trial comparing two surgical techniques.

MVA - manual vacuum aspiration (suction curettage), hCG - chorionic gonadotropin, TVS - transvaginal sonography, est - estimated outcome when evaluation criteria not fully comparable, D\&C - dilatation and curettage, POC - products of conception.

ical treatment, which had an overall success of 51.5 percent. Ten studies, with 1408 pooled patients, resulted in an overall success rate of 93.6 percent for surgical treatment. One of those studies was an RCT that compared suction with sharp D\&C in 270 patients. ${ }^{23}$ Sensitivity analysis comparing RCT outcomes with observational outcomes in clinical series was nearly identical for the surgical group but somewhat lower in the expectant treatment group (79.5 percent success for RCTs versus 96.2 percent for clinical series).

All of these studies are displayed in Table 6 Rates of successful outcomes for these three approaches to treatment are compared in terms of 95 percent confidence intervals. The results of expectant and surgical treatment are nearly the same, as are their overlapping ranges of confidence intervals.

\section{Discussion}

It is clear that most studies of treatment of incomplete abortion involve a surgical procedure, and that $D \& C$ is still the most common approach to treatment worldwide. For example, McKee et al ${ }^{6}$ studied four hospitals in England and reported in 1992 that $\mathrm{D} \& \mathrm{C}$ for incomplete abortion was by far the most common out-of-hours surgical procedure, accounting for 74 percent of all emergency gynecologic procedures. A more recent study in Vancouver, British Columbia, showed that 92.5 percent of women seen in hospital emergency departments for spontaneous abortion had D\&Cs, whereas 51 percent of women seeking care for this problem at their family physicians' offices also had D\&Cs. ${ }^{42}$ As noted earlier, however, D\&C still carries some risks despite its wide use.

The optimal treatment for spontaneous incom- 
Table 5. Results of Expectant, Medical, and Surgical Treatment of Spontaneous Abortion.

\begin{tabular}{|c|c|c|c|c|c|c|c|c|c|}
\hline Study & $\begin{array}{c}\text { Patients } \\
\text { No. }\end{array}$ & $\begin{array}{c}\text { Expectant } \\
\text { Success } \\
\%\end{array}$ & $\begin{array}{l}\text { SE } \\
\%\end{array}$ & $\begin{array}{c}\text { Patients } \\
\text { No. }\end{array}$ & $\begin{array}{c}\text { Medical } \\
\text { Success } \\
\%\end{array}$ & $\begin{array}{l}\mathrm{SE} \\
\%\end{array}$ & $\begin{array}{l}\text { Patients } \\
\text { No. }\end{array}$ & $\begin{array}{c}\text { Surgical } \\
\text { Success } \\
\%\end{array}$ & $\begin{array}{l}\mathrm{SE} \\
\%\end{array}$ \\
\hline Chipchase \& James, ${ }^{13} 1977^{*}$ & 19 & 94.7 & 0.05 & - & - & - & 16 & 93.8 & 0.06 \\
\hline Kaplan et al, ${ }^{14} 1996$ & 172 & 96.5 & 0.01 & - & - & - & - & _ & - \\
\hline Nielsen \& Hahlin, ${ }^{15} 1995^{*}$ & 103 & 76.7 & 0.04 & - & - & - & 52 & 89.0 & 0.04 \\
\hline Chung et al, ${ }^{16} 1994$ & 60 & 88.3 & 0.04 & 132 & 44.0 & 0.04 & - & - & - \\
\hline Haines et al, ${ }^{17} 1994$ & 32 & 100.0 & - & - & - & - & - & - & - \\
\hline Rulin et al, ${ }^{18} 1993$ & 49 & 98.0 & 0.02 & - & - & - & - & - & - \\
\hline Mansur,"11992 & 43 & 97.7 & 0.02 & - & - & - & - & - & - \\
\hline Ben-Baruch et al, ${ }^{19} 1991$ & 46 & 100.0 & - & - & - & - & 68 & 100.0 & - \\
\hline Letterie et al, ${ }^{20} 1991$ & 21 & 95.2 & 0.05 & - & - & - & - & - & - \\
\hline de Jonge et al, ${ }^{21} 1995^{*}$ & - & - & - & 23 & 13.0 & 0.07 & 27 & 96.0 & 0.04 \\
\hline Henshaw et al, 221993 & - & - & - & 43 & 95.3 & 0.03 & - & - & - \\
\hline Verkuyl \& Crowther, ${ }^{23} 1993^{\dagger}$ & - & - & - & - & - & - & 270 & 95.6 & 0.01 \\
\hline Kizza \& Rogo, ${ }^{24} 1990$ & - & - & - & - & - & - & 585 & 92.0 & 0.01 \\
\hline Farrell et al, ${ }^{25} 1982$ & - & - & - & - & - & - & 111 & 94.0 & 0.02 \\
\hline Marshall26 1971 & - & - & - & - & - & - & 86 & 88.0 & 0.03 \\
\hline Suter et al, ${ }^{27} 1970$ & - & - & - & - & - & - & 104 & 94.2 & 0.02 \\
\hline Tan et al, ${ }^{28} 1969$ & - & - & - & - & - & - & 89 & 98.9 & 0.01 \\
\hline Total & 545 & $\begin{array}{c}92.48 \\
(92.5 \%)\end{array}$ & 0.03 & 198 & $\begin{array}{c}51.54 \\
(51.5 \%)\end{array}$ & 0.05 & 1408 & $\begin{array}{c}93.58 \\
(93.6 \%)\end{array}$ & 0.02 \\
\hline
\end{tabular}

*Randomized controlled trials across treatment categories.

${ }^{\dagger}$ Randomized controlled trial comparing types of surgical treatment only.

SE - standard error.

plete abortion should be effective, safe, acceptable to patients, and readily available at lowest cost and risk. It is most appropriate that the long-held standard of care, the D\&C of whatever type, is now being called into question. Recent advances in medical approaches to induced abortion have engendered the question of whether alternative approaches would also be effective in the management of spontaneous incomplete abortion.

Unfortunately, we have found only three studies, all published since 1993, that deal with this question, and the answer so far is not promising. ${ }^{16,21,22}$ In a relatively small 1993 study, Henshaw et al ${ }^{22}$ reported a 95.3 percent success rate using a single $0.5-\mathrm{mg}$ dose of intramuscular sulprostone or a $400-\mu \mathrm{g}$ dose of oral misoprostol. The only two subsequent published studies, however, failed to replicate those good results, ${ }^{16,21}$ with the most recent study by de Jonge et al in 1995 showing only a 13 percent success rate after a single $400-\mu \mathrm{g}$ dose of oral misoprostol. The de Jonge et al study, however, might unfairly underestimate the potential of this form of treatment, because the study protocol called for a D\&C 12 hours after the misoprostol dose if the products of conception were not fully expelled. ${ }^{21}$ It could well be that a successful outcome would have occurred much more often given more time. It must also be kept in mind that prostaglandins are contraindicated for some women (eg, those with asthma and heart disease), and that if larger doses are required to gain increased effectiveness, gastrointestinal side effects are likely to increase as well (usually nausea, vomiting, and diarrhea). Based on a large recent study of induced abortion, combination therapy with a prostaglandin and antiprogesterone agent might be more effective than with a single agent. $^{43}$

The nine studies retrieved for expectant treatment offer solid evidence that this approach is feasible and indeed indicated for at least a subgroup of patients with spontaneous incomplete abortion. ${ }^{11,13-20}$ There seems to be no question that this approach is safe and effective for all those patients who have empty uteri by transvaginal sonography (TVS). In their 1994 study, Haines et al found that 64 percent of 50 consecutive patients with spontaneous abortion had empty uteri by TVS. ${ }^{17}$ Only two of the nine published studies so far have assessed such treatment for patients who have residual products of conception by TVS. Nielsen and Hahlin ${ }^{15}$ reported a 79 percent success rate for ex- 
Table 6. Results of Expectant, Medical, and Surgical Treatment of Spontaneous Abortion, With Overall Confidence Intervals ( 95 percent).*

\begin{tabular}{lcccc}
\hline Treatment & $\begin{array}{c}\text { Pooled } \\
\text { Number }\end{array}$ & $\begin{array}{c}\text { Pooled Success } \\
\text { Weighted } \\
\text { Average, } \%\end{array}$ & $\begin{array}{c}\text { Standard Error } \\
\text { Weighted } \\
\text { Average }\end{array}$ & $\begin{array}{c}\text { Confidence } \\
\text { Interval (95\%) } \\
\text { Range }\end{array}$ \\
\hline $\begin{array}{l}\text { Expectant } \\
\text { Randomized controlled trials (2 studies) }\end{array}$ & 122 & & & \\
Clinical series (7 studies) & 423 & 99.5 & 0.05 & $69.7-89.3$ \\
All studies (9 studies) & 545 & 92.5 & 0.03 & $90.3-102.1$ \\
Medical & 198 & 51.5 & 0.03 & $86.6-98.4$ \\
Surgical & & & 0.05 & $51.7-71.3$ \\
Randomized controlled trials (3 studies) & 95 & 91.8 & 0.05 & $82.0-101.6$ \\
Clinical series (7 studies ${ }^{\dagger}$ ) & 1313 & 93.8 & 0.02 & $89.9-97.7$ \\
All studies (10 studies) & 1408 & 93.6 & 0.02 & $89.7-97.5$ \\
\hline
\end{tabular}

*Includes sensitivity analysis comparing outcomes of randomized controlled trials versus clinical series and all studies for expectant and surgical treatment categories.

tVerkuyl and Crowther ${ }^{23}$ study included in clinical series for sensitivity analysis, because it was comparing two surgical techniques only.

pectant management when products of conception or blood clots measured 15 to $50 \mathrm{~mm}$ by TVS (anteroposterior diameter). (Success was documented by disappearance of products of conception by TVS 3 days after the patient sought care.) In the most recent study (1997), Chipchase and James ${ }^{13}$ showed a 94.7 percent success rate, though their study was small (19 patients in the expectant group). The investigators in these two studies admit that their sonographic inclusion criteria are arbitrary; it is still unknown what limit in size of products of conception by TVS is the appropriate upper cutoff point for expectant treatment.

The sensitivity analysis comparing RCT outcomes with those in observational studies of expectant treatment show a lower, though still respectable, pooled success average of 79.5 percent for the RCT subgroup of 122 pooled patients. This difference appears to be due to the 76.7 percent successful outcome found by Nielsen and Hahlin in their 103 patients. Twenty-one percent of their expectant treatment subgroup had a D\&C if a TVS after 3 days showed products of conception of more than $15 \mathrm{~mm}$ in anteroposterior diameter. It could well be that the 76.7 percent success figure might have been considerably higher had these patients been followed expectantly for a longer period. ${ }^{15}$

Another key marker to consider for expectant treatment is the chorionic gonadotropin level. If the products of conception are not examined, an ectopic pregnancy could be missed. Chorionic gonadotropin levels that rise or persist might be the only indication of an ectopic pregnancy, which could have been missed clinically or by TVS. Though most studies have shown that these levels return to normal by 3 weeks, Letterie et al ${ }^{20}$ found that one patient's levels did not do so for 97 days. The appropriate intervals between serial measurements are not entirely clear. In their excellent study, Letterie et al measured serum chorionic gonadotropin levels at intervals of 2 to 7 days until they dropped to levels below $10 \mathrm{mIU} / \mathrm{mL} .{ }^{20}$

Several limitations of this study bear comment. First, formal statistical techniques were not possible because of the small number of RCTs retrieved from the literature. Second, most studies to date of medical treatment of abortion involve induced abortion, with only three studies available to assess outcomes of medical treatment of spontaneous inevitable or incomplete abortion. Third, because at least a few of the patients experiencing $\mathrm{D} \& \mathrm{C}$ for incomplete abortion might have been bleeding more heavily or were more symptomatic in other ways than patients receiving expectant treatment, some degree of selection bias is unavoidably introduced into the comparison of treatment outcomes. Fourth, simple pooled and weighted averages do not constitute statistical comparisons of the treatment alternatives, although they do provide much needed quantification of existing studies to make better evidencebased decisions among treatment options.

There is clearly a need for further research on treatment alternatives for this common problem. Several investigators have called for additional 


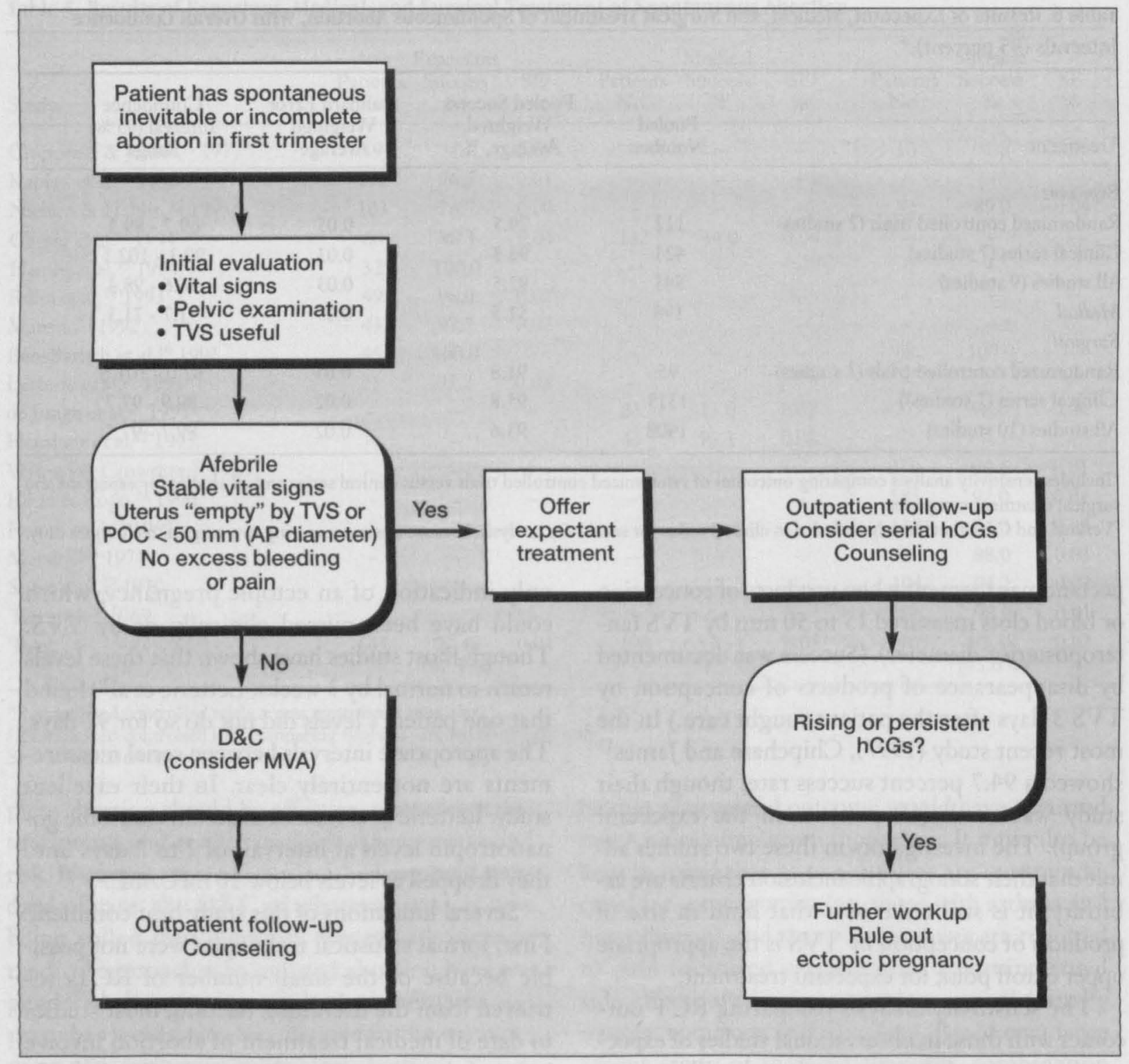

Figure 1. Proposed approach to management of spontaneous inevitable or incomplete abortion in first trimester. TVS - transvaginal sonography, POC - product of conception, AP - anteroposterior, hCG - chorionic gonadogropin, D\&C - dilatation and curettage, MVA - manual vacuum aspiration.

RCTs of treatment options. It is hoped that expectant treatment will be compared with surgical approaches in larger RCTs with wider inclusion criteria for TVS cutoffs than have been studied to date (and possibly even without the use of TVS), thereby exploring how widely expectant treatment might be safely offered to women with spontaneous incomplete abortion during the first trimester. Also needed are patient preference studies that incorporate the latest research findings into clinical scenarios by which women can better select their choice of treatment. In the meantime, based on present findings of this pooled quantitative literature evaluation and pending the out- comes of further research, the pathway of care shown in Figure 1 is proposed as a reasonable evidence-based approach to treatment of this common problem.

\section{Conclusions}

Based upon this pooled quantitative literature evaluation, the following conclusions can be drawn:

1. It is time to reassess the role of D\&C in the treatment of spontaneous inevitable and incomplete abortion in the first trimester.

2. Although only a limited number of published studies (all since 1991) have examined the outcomes of expectant treatment of spontaneous 
incomplete abortion in the first trimester, the evidence from nine studies and 545 pooled patients supports its use in selected patients.

3. Many patients with this problem can be cared for safely and effectively by expectant treatment if their blood pressure and heart rate are stable, if they have no excess bleeding or unacceptable pain, and if they are afebrile.

4. Transvaginal sonography (TVS) can be useful as an aid to patient selection for expectant treatment.

5. If expectant treatment is chosen, the clinician should consider monitoring chorionic gonadotropin levels to rule out the possibility of ectopic pregnancy.

6. Pending further studies, there is not yet sufficient evidence for medical treatment of incomplete abortion.

7. Surgical treatment is indicated in the presence of continued brisk vaginal bleeding, infection, or unacceptable pain and probably for gestations of greater than 13 weeks.

8. Although further research is needed to clarify the parameters and indications for expectant treatment and to assess informed patient preferences among their therapeutic choices, expectant treatment is the initial treatment of choice for many patients with spontaneous inevitable or incomplete abortion in the first trimester.

\section{References}

1. Laferla JJ. Spontaneous abortion. Clin Obstet Gynaecol 1986;13:105-14.

2. Shapiro S, Abramowicz CM. Pregnancy outcome correlates identified through medical record-based information. Am J Public Health Nations Health 1969;59:1629-50.

3. Warburton D, Fraser FC. Spontaneous abortion risks in man. Data from reproductive histories collected in a medical genetics unit. Hum Genet 1964;16:1-25.

4. Spontaneous abortion in primary care. A report from ASPN.J Am Board Fam Pract 1988;1:15-23.

5. Hertig AT, Livingstone RG. Spontaneous, threatened and habitual abortion. Their pathogenesis and treatment. N Engl J Med 1944;26:797-806.

6. McKee M, Priest P, Ginzler M, Black N. Can outof-hours operating in gynecology be reduced? Arch Emerg Med 1992;9:290-8.

7. Farrell RG, Stonington DT, Ridgeway RA. Incomplete and inevitable abortion: treatment by suction curettage in the emergency department. Ann Emerg
Med 1982;11:652-8.

8. Jensen PA, Stromme WB. Amenorrhea secondary to puerperal curettage (Asherman's sundrome). Am J Obstet Gynecol 1972;113:150-7.

9. Forssman L. Posttraumatic intrauterine synechiae and pregnancy. Obstet Gynecol 1965;26:710-3.

10. Klein SM, Garcia CR. Asherman's syndrome: a critique and current review. Fertil Steril 1973;24:722-35.

11. Mansur MM. Ultrasound diagnosis of complete abortion can reduce need for curettage. Eur J Obstet Gynecol Reprod Biol 1992;44:65-9.

12. Petitti DB. Meta-analysis, decision analysis and costeffectiveness analysis: methods for quantitative synthesis in medicine. New York: Oxford University Press, 1994.

13. Chipchase J, James D. Randomised trial of expectant versus surgical management of spontaneous miscarriage. Br J Obstet Gynaecol 1997;104:840-1.

14. Kaplan B, Pardo J, Rabinerson D, Fisch B, Neri A. Future fertility following conservative management of complete abortion. Hum Reprod 1996;11:92-4.

15. Nielsen S, Hahlin M. Expectant management of first-trimester spontaneous abortion. Lancet 1995; 345:84-6.

16. Chung TK, Cheung LP, Lau WC, Haines CJ, Chang AM. Spontaneous abortion: a medical approach to management. Aust NZJ Obstet Gynaecol 1994;34:432-6.

17. Haines CJ, Chung T, Leung DY. Transvaginal sonography and the conservative management of spontaneous abortion. Gynecol Obstet Invest 1994; 37:14-7.

18. Rulin MC, Bornstein SG, Campbell JD. The reliability of ultrasonography in the management of spontaneous abortion, clinically thought to be complete: a prospective study. Am J Obstet Gynecol 1993;168(1 Pt 1):12-5.

19. Ben-Baruch G, Schiff E, Moran O, Menashe Y, Mashiach S, Menczer J. Curettage vs. nonsurgical management in women with early spontaneous abortions. The effect on fertility. J Reprod Med 1991; 36:6446.

20. Letterie GS, Hibbert ML, Ramirez EJ. Expectant management of abnormal concentrations of human chorionic gonadotropin during the first trimester of pregnancy. Gynecol Obstet Invest 1991;31:176-8.

21. de Jonge ET, Makin JD, Manefeldt E, De Wet GH, Pattinson RC. Randomised clinical trial of medical evacuation and surgical curettage for incomplete miscarriage. BMJ 1995;311:662.

22. Henshaw RC, Cooper K, el Refaey H, Smith NC, Templeton AA. Medical management of miscarriage: non-surgical uterine evacuation of incomplete and inevitable spontaneous abortion. BMJ 1993;306: 894-5.

23. Verkuyl DA, Crowther CA. Suction v conventional 
curettage in incomplete abortion. A randomised controlled trial. S Afr Med J 1993;83:13-5.

24. Kizza AP, Rogo KO. Assessment of the manual vacuum aspiration (MVA) equipment in the management of incomplete abortion. East Afr Med J 1990; 67: 812-22

25. Farrell RG, Stonington DT, Ridgeway RA. Incomplete and inevitable abortion: treatment by suction curettage in the emergency department. Ann Emerg Med 1982;11:652-8.

26. Marshall BR. Emergency room vacuum curettage for incomplete abortion.J Reprod Med 1971;6:177-8

27. Suter PE, Chatfield WR, Kotonya AO. The use of suction curettage in incomplete abortion. J Obstet Gynaecol Br Commonw 1970;77:464-6.

28. Tan PM, Ratnam SS, Quek SP. Vacuum aspiration in the treatment of incomplete abortion. J Obstet Gynaecol Br Commonw 1969;76:834-6.

29. Mahomed K, Healy J, Tandon S. A comparison of manual vacuum aspiration (MVA) and sharp curettage in the management of incomplete abortion. Int J Gynaecol Obstet 1994;46:27-32.

30. Filshie GM, Sanders RR, O'Brien PM, Overton J, Khattab T, Oats JJ. Evacuation of retained products of conception in a treatment room and without general anaesthesia. Br J Obstet Gynaecol 1977; 84:514-6.

31. Allen A, Philpott RH. Management of incomplete abortion as an outpatient procedure. Cent Afr J Med 1971;17:91-6.

32. Hill DL. Management of incomplete abortion with vacuum curettage. Minn Med 1971;54:225-8.

33. Rashid S, Smith P. Suction evacuation of uterus for incomplete abortion. J Obstet Gynaecol Br Commonw 1970;77:1047-8.

34. Eaton CJ, Doil KL. Uterine aspiration in the management of incomplete abortion. Surg Gynecol Obstet 1969;129:588-9.

35. Gibbs CE, Rayner DA. Treatment room curettage after spontaneous incomplete abortion. GP 1968; 38:124-6.

36. Breen JL, Peraglie BR, Caterini HR. Aggressive management of incomplete abortion. GP 1967;35: 108-14.

37. Decenzo JA, Cavanagh D. Management of incomplete abortion on an outpatient basis. Am J Obstet Gynecol 1967;97:17-20.

38. Peretz A, Grunstein S, Brandes JM, Paldi E. Evacuation of the gravid uterus by negative pressure (suction evacuation). Am J Obstet Gynecol 1967;98: 18-22.

39. Macourt D. Incomplete abortion: an analysis of one method of management of incomplete abortion. Med J Aust 1966;2:640-2.

40. Levin AC, Rizzi JN, Veprovsky EC. Management of incomplete abortion. Am J Obstet Gynecol 1962; 83:9-12.

41. Russell PB. Abortions treated conservatively: A 12year study covering 3,739 cases. South Med J 1947; 40:314-4.

42. Wiebe E, Janssen P. Management of spontaneous abortion in family practices and hospitals. Fam Med 1998;30:293-6.

43. Spitz LM, Bardin CW, Benton L, Robbins A. Early pregnancy termination with mifepristone and misoprostol in the United States. N Engl J Med 1998; 